\title{
Evaluation of Anticorrosive Coatings on Carbon Steel in Marine Environments: Accelerated Corrosion Test and Field Exposure
}

\author{
Rosa Vera ${ }^{1, *}$, Estefanía Cruz $^{1}$, Margarita Bagnara $^{1}$, Raquel Araya ${ }^{1}$, Rodrigo Henríquez, ${ }^{1}$, \\ Andrés Díaz-Gómez ${ }^{1}$, Paula Rojas ${ }^{2}$ \\ ${ }^{1}$ Institute of Chemistry, College of Science, Pontificia Universidad Católica de Valparaiso, Av. \\ Universidad 330, Placilla (Curauma), Valparaiso, Chile. \\ ${ }^{2}$ School of Design, Universidad Adolfo Ibáñez, Diagonal Las Torres 2640, Santiago, Chile \\ *E-mail: rosa.vera@pucv.cl
}

doi: $10.20964 / 2018.01 .66$

Received: 22 September 2017 / Accepted: 19 November 2017 / Published: 16 December 2017

\begin{abstract}
This study assesses the behavior of two paint systems applied to A-36 steel, commonly used to cover industrial structures in marine environments. Accelerated tests were carried out in a salt spray chamber with a maximum of 3000 hours of exposure, while other tests were conducted in the field in five areas in Chile over a period of two years. Coatings were assessed with measurements of thickness, adherence, and blistering. The behaviors of these coatings were assessed using electrochemical impedance spectroscopy (EIS techniques, measuring the evolution of an impedance module at $0.1 \mathrm{~Hz}$. The results show that, after two years of exposure or after 3000 hours in the salt spray chamber, the two coatings still present adequate protective properties, with an impedance module value $\log |\mathrm{Z}|$ greater than $10^{6} \Omega \mathrm{cm}^{2}$. However, for all tests, comparing C5MB and C5IB coating systems, the latter is always less protective for the steel.
\end{abstract}

Keywords: Atmospheric exposure, accelerated test, corrosion, carbon steel, organic coatings.

\section{FULL TEXT}

(C) 2018 The Authors. Published by ESG (www.electrochemsci.org). This article is an open access article distributed under the terms and conditions of the Creative Commons Attribution license (http://creativecommons.org/licenses/by/4.0/). 